\title{
In silico evaluation of antimicrobial, antihyaluronidase and bioavailability parameters of rosmarinic acid in Perilla frutescens leaf extracts
}

\author{
Hui-Zhen $\mathrm{Li}^{1} \cdot$ Zhiqing Ren $^{1} \cdot$ N. V. Reddy ${ }^{1}$ Tianyu Hou ${ }^{1} \cdot$ Zhi-Jun Zhang $^{1}$
}

Received: 13 May 2020 / Accepted: 10 August 2020 / Published online: 25 August 2020

(c) Springer Nature Switzerland AG 2020

\begin{abstract}
The present study reports ultrasound-assisted extraction of rosmarinic acid extract using the leaves of Perilla frutescens L. by using ethanol solvent. P. frutescens rosmarinic acid extract (PF-RAE) exhibited antimicrobial activity against bacteria and fungi. PF-RAE exhibited excellent antioxidant activity against DPPH and ABTS radicals. PF-RAE exhibited significant in vitro hyaluronidase inhibitory activity with maximum inhibition of $44.35 \%$. HPLC analysis showed that rosmarinic acid is the major component of PF-RAE and it is responsible for antimicrobial, antioxidant and hyaluronidase inhibitory activities. Further, we report some of the plausible mechanisms of multiple biological functions of rosmarinic acid by in silico studies. Molecular docking studies reported that rosmarinic acid strongly inhibits bacterial co-/posttranslation enzyme peptide deformylase (promising antibacterial target) as well as fungi posttranslation enzyme $\mathrm{N}$-myristoyltransferase (promising antifungal target) with binding affinities of 7.9 and $7.1 \mathrm{Kcal} / \mathrm{mol}$, respectively. Further, rosmarinic acid exhibited strong affinity with human hyaluronidase protein by $\mathrm{H}$-bonding interactions. Rosmarinic acid satisfactorily follows the Lipinski's rule of five with ' 0 ' violations, showed excellent hydrophilicity, oral bioavailability, skin permeability and gastrointestinal permeability and showed no toxicity at all. We concluded that rosmarinic acid can be developed as an excellent pharmaceutical and nutraceutical drug ingredient.
\end{abstract}

Keywords Perilla frutescens · Rosmarinic acid · HPLC analysis · Antioxidant activity · Hyaluronidase inhibition · Lipinski's rule of five

\section{Introduction}

Extracellular matrix of the skin consists of fibrous proteins (collagen, elastin, laminins and fibronectins) and proteoglycans (glycosaminoglycans). Hyaluronic acid (HA) is the predominant glycosaminoglycan present in the human skin. Fifty percentage of total HA in the body is present only in the skin tissue [1]. Due to its cationic and extreme hydrophilic nature, HA has high capacity to retain water molecules and maintains skin moisture, smoothness of skin, lubricant nature and youthful appearance of skin [2]. HA is approved by USFDA as an injectable for the correction of wrinkles, pimples and facial lines. With advancing age, HA content will be reduced and HA polymers will be degraded, resulting in the loss of skin moisture leading to skin dryness, wrinkling, epidermal atrophy, laxity, leathery appearance and loss of elasticity and smoothness [3]. In addition to normal aging process (intrinsic aging), external

Electronic supplementary material The online version of this article (https://doi.org/10.1007/s42452-020-03323-8) contains supplementary material, which is available to authorized users.

Zhi-Jun Zhang, zjzhang@nuc.edu.cn; sxzzj@163.com | 'School of Chemical Engineering and Technology, North University of China, No. 3 Xueyuan Road, Taiyuan 030051, Shanxi Province, China. 
factors such as air pollution, dietary changes (junk foods, untimely food habits), long-term exposure to radiations and hazardous chemicals, UV irradiation, insomnia, skin injuries, work and personal stress produce reactive oxygen species (ROS). These ROS interact and cause degradation of HA leading to the loss of skin moisture and integrity, a condition called extrinsic aging. Extrinsic aging is characterized by wrinkles of skin, dryness and loss of smoothness [4].

Homoeostasis and turnover of the HA in the skin are maintained by HA synthases and HA-degrading enzymes (hyaluronidases). The decrease in the levels of HA is associated with decreased expression of HA synthase and increased expression of hyaluronidase $[5,6]$. Hyaluronidase hydrolyzes HA at hexosaminidic $\beta$ (1-4) linkage and causes its degradation, resulting in loss of structural and functional integrity of skin. Intrinsic aging, extrinsic aging, allergy, atopic dermatitis and inflammation lead to increased expression levels of hyaluronidase [6]. The inhibition of hyaluronidase prevents or slows down the degradation of HA in the skin and maintains structural and function integrity of skin [5-7]. Hyaluronidase inhibitors maintain homeostasis of hyaluronic acid and may serve as antiaging and antioxidant agents. Further, hyaluronidase plays a critical role in allergic and inflammatory reactions by stimulating the mast cell degradation and expression of inflammatory genes. Hence, hyaluronidase inhibitors serve as antiallergic and antiinflammatory agents $[8,9]$. HA is widely distributed in other tissues of the body including connective and neural tissues. Hence, homeostasis of HA is very important for normal mobility of body as it keeps tendons, ligaments and joints very healthy. HA degradation by hyaluronidase is associated with joint diseases and slows down the wound healing, repair and regeneration. Hence, hyaluronidase inhibitors play a potential role in the proper maintenance and healthy nature of epithelial (skin) and connective (bone) tissues [10,11]. Due to side effects of synthetic drugs, natural hyaluronidase inhibitors have gained attention of researchers.

Perilla frutescens (L.) belongs to the mint family Lamiaceae. It is widely distributed in China, Japan, Korea, India and other Southeast Asian countries [12]. In China, it is cultivated as a food crop and used for nutraceutical and medicinal purposes. In traditional Chinese medicine, the leaves of $P$. frutescens have been extensively used in the preparation of herbal medicines for the treatment of allergy, asthma, cough and teeth cavities [13]. In China, Japan and Korea, perilla tea is popular as it gives relief due to its antioxidant nature. Perilla leaves are great source of antioxidants, and it helps in decreasing the damage by free radicals and lessens the aging. The antioxidant effect of perilla leaves helps in healthy blood circulation by lowering the lipid peroxidation and bad cholesterol [14].
The leaves of this plant constitute phenolic compounds such as rosmarinic acid, caffeic acid, protocatechuic acid, chlorogenic acid and their derivatives. Flavonoids such as apigenin, luteolin, scutellarein, catechin, negletein and vicenin were reported from the leaves of $P$. frutescens. The leaves of $P$. frutescens contain various important phenylpropanoids, alkaloids, terpenoids, anthocyanins, coumarins and neolignans [15]. Owing to possessing different active constituents, the leaves of $P$. frutescens exhibited different biological activities including antimicrobial, antifungal, antioxidant, antidiabetic, hypolipidemic, hepatoprotective, antidepressant, antiallergic, antiinflammatory and anticancer activities. Among the different bioactive constituents that $P$. frutescens leaves possess, rosmarinic acid was found in higher amounts. Along with rosmarinic acid, three different derivatives of rosmarinic acid were reported from the leaves of $P$. frutescens including methyl rosmarinic acid, rosmarinic acid-3-O-glucoside and 3'-dehydroxyl-rosmarinicacid-3-Oglucoside $[15,16]$.

In the present study, we prepared the rosmarinic acid extract using the leaves of $P$. frutescens. Rosmarinic acid extract was prepared using ethanol solvent by employing ultrasound-assisted extraction method. Ultrasound-assisted rosmarinic acid extract of $P$. frutescens (PF-RAE) was used for further studies. The purity and quantity of rosmarinic acid in PF-RAE were determined by spectroscopic method and high-performance liquid chromatography (HPLC) analysis. As-prepared PF-RAE was evaluated for multiple biological functions including in vitro hyaluronidase inhibition, in vitro antioxidant and antimicrobial activities. Antimicrobial activity of the PF-RAE was evaluated against Gram-negative (Escherichia coli) and Gram-positive (Staphylococcus aureus) bacteria as well as human fungal pathogen Candida albicans. In vitro antioxidant activity of the PF-RAE was evaluated by free radical scavenging assays including 2,2-diphenyl-1-picrylhydrazyl (DPPH) and 2,2'-azino-bis(3-ethylbenzothiazoline-6-sulphonic acid) (ABTS) scavenging assays. Further, molecular docking studies were performed between ligand rosmarinic acid and various proteins including bacterial peptide deformylase, fungal $\mathrm{N}$-myristoyltransferase and human hyaluronidase enzyme. Pharmacokinetics, drug likeness, Lipinski's rule of five and bioavailability score of rosmarinic acid were evaluated by SwissADME software. Bioactivity score of rosmarinic acid was evaluated by Molinspiration software. Toxicity risk properties of rosmarinic acid were predicted using admetSAR and Osiris property explorer. 


\section{Materials and methods}

\subsection{Collection of plant material}

The leaves of $P$. frutescens were collected from the cultivating fields nearby North University of China, Taiyuan, Shanxi Province, China. The leaves were washed twice with distilled water (DW) to remove the dust and shade-dried the leaves. After drying, the leaves were ground into fine powder.

\subsection{Ultrasound-assisted extraction}

Ultrasound-assisted extraction of rosmarinic acid was carried out according to the method of Zhou et al. [17] with some modifications. Ten grams of fine leaf powder of $P$. frutescens was taken into $200 \mathrm{~mL}$ of absolute ethanol. Extraction process was carried out in an ultrasonicator (Ningbo Scientz SB-5200; power of 300 W, temperature of $50^{\circ} \mathrm{C}$; duration of $45 \mathrm{~min}$ ) for two times. The extracts were combined and taken in the rotavapor for the complete removal of solvent. Then, the residue was collected and air-dried. The extract was named as rosmarinic acid extract of $P$. frutescens (PF-RAE) and used for further studies.

\subsection{Estimation of total phenolic content (TPC) of PF-RAE}

TPC of PF-RAE was determined by using Folin-Ciocalteu $(\mathrm{F}-\mathrm{C})$ method [18]. One milliliter of each extract $(1 \mathrm{mg} / \mathrm{mL})$ was taken in a $50-\mathrm{mL}$ flask. To this extract, $1 \mathrm{~mL}$ of $\mathrm{F}-\mathrm{C}$ reagent and $10 \mathrm{~mL}$ of $7 \% \mathrm{Na}_{2} \mathrm{CO}_{3}$ were added. This mixture was vigorously mixed for $3 \mathrm{~min}$, and then, $13 \mathrm{~mL}$ of DW was added and mixed thoroughly; then, the mixture was incubated in the dark at room temperature for $90 \mathrm{~min}$. After incubation, the absorbance values were measured at $760 \mathrm{~nm}$. TPC of PF-RAE was calculated based on gallic acid (GA) standard curve. The TPC was expressed as milligram of GA equivalents/gram of dried sample (mg GAE/g).

\subsection{Fourier transform infrared (FTIR) analysis of PF-RAE}

FTIR analysis (Bruker, Karlsruhe, Germany) of PF-RAE was carried out between 500 and $4000 \mathrm{~cm}^{-1}$ to determine the functional groups present in PF-RAE.

\subsection{HPLC analysis of PF-RAE}

HPLC analysis of PF-RAE was carried out using Agilent LC (model: 1260 Infinity II HPLC system, Agilent Technologies
Inc., USA). The wavelengths 280 and $320 \mathrm{~nm}$ were selected for the detection of compounds in PF-RAE using 1260 Infinity II Variable Wavelength detector (dual-wavelength mode). Gradient analysis was carried out using $0.1 \%$ glacial acetic acid (mobile phase A) and methanol (mobile phase B). Gradient phase conditions are $0-5 \min 20-40 \%$ (B), 5-10 min 40-55\% (B), 10-15 min 55-60\% (B), 15-20 min $60-65 \%$ (B), 20-25 min 65-70\% (B), 25-30 min 70-60\% (B), 30-35 min $60-55 \%$ (B) and $35-40$ min $55-50 \%$ (B). Ten microliters of test sample was injected and run through C18-RP column at a flow rate of $1 \mathrm{~mL} / \mathrm{min}$ at $35^{\circ} \mathrm{C}$ of column temperature.

\subsection{Estimation of rosmarinic acid content of PF-RAE}

Rosmarinic acid content of PF-RAE was determined according to the method of Lopez-Amotdos et al. [19]. Briefly, $0.2 \mathrm{~mL}$ of PF-RAE was added to $4.0 \mathrm{~mL}$ of sodium acetate buffer $(0.1 \mathrm{M}, \mathrm{pH} 6.0)$. To this mixture, $30 \mu \mathrm{L}$ of ferrous sulfate solution $(0.2 \mathrm{M})$ and $0.77 \mathrm{~mL}$ of $\mathrm{DW}$ were added. The reaction mixture was mixed thoroughly and kept as such for $10 \mathrm{~min}$ at room temperature. After $10 \mathrm{~min}$, the absorbance of the reaction mixture was recorded at $568 \mathrm{~nm}$ using a UV-visible spectrophotometer (UV9600, Bobang Co., China). RA content was determined as milligram per gram dry weight ( $\mathrm{mg} / \mathrm{g} D W$ ) of perilla leaf powder.

\subsection{In vitro biological effects of PF-RAE}

\subsubsection{Antimicrobial activity of PF-RAE}

Antibacterial activity of PF-RAE was checked by disc diffusion assay [20] against both Gram positive (S. aureus) and Gram negative (E. coli). In this study, Luria-Bertani (LB) bacterial growth media were taken into Petri plates. Two hundred microliters of bacterial inoculum was spread on the surface of LB plates. Then, sterile paper discs were kept on the surface of $L B$ plates. Thereafter, first three discs were impregnated, respectively, with 5,10 and $15 \mu \mathrm{L}$ of PF-RAE ( $1 \mathrm{mg} / \mathrm{mL}$ ) using micropipette. Then, the plates were incubated for $24 \mathrm{~h}$ at $37^{\circ} \mathrm{C}$. After $24 \mathrm{~h}$, the plates were checked for inhibition zones and the diameter of inhibition zones was measured in millimeters. Further, antifungal activity of PF-RAE was checked by employing disc diffusion assay against $C$. albicans [21]. Potato dextrose agar (PDA) fungal growth media were taken into Petri plates. Two hundred microliters of fungal inoculum was spread on the surface of PDA plates. Then, sterile paper discs were kept on the surface of PDA plates. Discs were impregnated with 5, 10 and $15 \mu \mathrm{L}$ of PF-RAE ( $1 \mathrm{mg} / \mathrm{mL})$. Plates were incubated for $72 \mathrm{~h}$ at $25^{\circ} \mathrm{C}$. After $72 \mathrm{~h}$, the plates were checked for inhibition zones and the diameter of inhibition zones was measured in millimeters. 


\subsubsection{Antioxidant activity of PF-RAE}

In vitro antioxidant activity of PF-RAE was carried out by free radical scavenging assays including DPPH and ABTS scavenging assays. DPPH scavenging assay of PF-RAE was checked according to the method of Shimada et al. [22]. Briefly, $1 \mathrm{~mL}$ of each extract $(20,40,60,80$, and $100 \mu \mathrm{g} / \mathrm{mL})$ was added to $2 \mathrm{~mL}$ of DPPH radical ( $1 \mathrm{~m} \mathrm{M} / \mathrm{L})$. This reaction solution was mixed well for $3 \mathrm{~min}$ and then incubated for $30 \mathrm{~min}$ in the dark at room temperature. After incubation, the absorbance values were recorded at $517 \mathrm{~nm}$. DPPH scavenging activity was determined by the formula $\%$ Scavenging $=[$ (Absorbance of control - Absorbance of test sample)/Absorbance of control] $\times 100$. Further, ABTS scavenging assay of PF-RAE was checked according to the method of Re et al. [23]. To $2.45 \mathrm{mM}$ potassium persulfate, $7 \mathrm{mM}$ ABTS was added, and the mixture was incubated for $12-16 \mathrm{~h}$ in the dark until the absorbance was stable. This ABTS radical cation solution is diluted with $70 \%$ ethanol to an absorbance of $0.700-0.02$ at $734 \mathrm{~nm} .0 .9 \mathrm{~mL}$ of this solution was added to $0.1 \mathrm{~mL}$ of test samples $(20,40,60$, 80 and $100 \mu \mathrm{g} / \mathrm{mL}$ ) and mixed well for $45 \mathrm{~s}$. The reaction solution was incubated in the dark for $15 \mathrm{~min}$, and then, the absorbance was measured at $734 \mathrm{~nm}$. ABTS scavenging activity was determined by the formula \%Scavenging $=[$ (Absorbance of control - Absorbance of test sample)/Absorbance of control] $\times 100$.

\subsubsection{Hyaluronidase inhibitory activity of PF-RAE}

In vitro hyaluronidase inhibitory activity of PF-RAE was determined using the method of Morgan and Elson [24]. Briefly, $0.05 \mathrm{~mL}$ of $\mathrm{CaCl}_{2}$ solution $(2.5 \mathrm{~mol} / \mathrm{L}$ ) was added into four 10-mL tubes marked with $A, B, C$ and $D$, respectively. $0.25 \mathrm{~mL}$ of acetic acid buffer was added into two tubes $A$ and $C .0 .25 \mathrm{~mL}$ of hyaluronidase $(500 \mathrm{u} / \mathrm{mL})$ was added into tubes $B$ and $D$. Four tubes were incubated for $20 \mathrm{~min}$ at $37^{\circ} \mathrm{C}$. Then, $0.25 \mathrm{~mL}$ of the each extract was added separately to each of the tubes $A$ and B. $0.25 \mathrm{~mL}$ of DW was added to the $C$ and $D$ tubes. Then, the four tubes were incubated for $20 \mathrm{~min}$ at $37^{\circ} \mathrm{C}, 0.25 \mathrm{~mL}$ of sodium hyaluronate was added to the tubes $B$ and $D$, and $0.25 \mathrm{~mL}$ of acetate buffer was added to the tubes $A$ and $C$. Thereafter, all the four tubes were incubated at $37^{\circ} \mathrm{C}$ for $40 \mathrm{~min}$. Then, $0.05 \mathrm{~mL}$ of $\mathrm{NaOH}, 0.5 \mathrm{~mL}$ of acetylacetone and $0.25 \mathrm{~mL}$ of DW were added. Then, the tubes were boiled for $30 \mathrm{~min}$ and then allowed to cool on ice bath. Finally, $0.5 \mathrm{~mL}$ of $p$-dimethyl amino benzaldehyde chromogenic reagent solution was added to four tubes and left at room temperature for $30 \mathrm{~min}$. The absorbance values were recorded at $530 \mathrm{~nm}$. The percentage of hyaluronidase inhibition was calculated by the formula $\mathrm{HI}(\%)=[(A-B)-(C-D)] /(A-B$ )$\times 100$, where ' $A$ ' is the absorbance of reaction solution (acetate buffer + sample + acetate buffer) solution, ' $B$ ' is the absorbance of reaction solution (hyaluronidase + sample + sodium hyaluronate) solution, ' $C$ ' is the absorbance of reaction solution (acetate buffer + DW + acetate buffer) and ' $D$ ' is the absorbance of reaction solution (hyaluronidase + distilled water + sodium hyaluronate).

\subsection{In silico studies}

\subsubsection{Molecular docking}

3D structure of the ligand rosmarinic acid was retrieved from NCBI PubChem (PubChem CID: 5281792). Crystal structures of proteins such as bacterial peptide deformylase complexed with antibiotic actinonin (PDBID: 1 LRU), fungal $N$-myristoyltransferase of $C$. albicans (PDBID: 1IYL) and human hyaluronidase (PDBID: 2PE4) were retrieved from Protein Data Bank (RCSBPDB). Water molecules were removed, and hydrogen atoms were added to protein molecules by $3 \mathrm{D}$ protonation using molecular operating environment (MOE) software. Then, partial charges were added to atoms of proteins using AMBER 99. Energy minimization was carried out using MMFF94x force field to get stable protein conformers. The active site of the protein was identified by Site Finder of MOE. The ligand was docked into the protein active site using parameters of MOE: triangle matcher algorithm, rescoring and London dG function. Best configurations were saved, and binding affinity (Kcal/ $\mathrm{mol}$ ) and binding interactions were determined.

\subsubsection{Pharmacokinetics and drug-likeness evaluation of rosmarinic acid}

Pharmacokinetics and drug-likeness evaluation parameters including Lipinski's rule of five, water solubility (Log S), bioavailability score, gastrointestinal absorption, blood-brain barrier permeation, skin permeation ( Log Kp) and ADMET (absorption, distribution, metabolism, excretion and toxicity) parameters were evaluated using different software including SwissADME, Molinspiration and Osiris property explorer.

\subsubsection{Bioactivity score prediction}

Bioactivity score of a compound or drug will be predicted based on six parameters including GPCR ligand, nuclear receptor ligand, ion channel modulator, kinase inhibitor, protease inhibitor and enzyme inhibitor. In this study, bioactivity score of rosmarinic acid was evaluated by software Molinspiration (https://molinspiration.com/). 


\section{Results and discussion}

In the present study, we prepared rosmarinic acid extract by ultrasound-assisted extraction method using the fine dried leaf powder of $P$. frutescens as source material and ethanol as extraction solvent. The rosmarinic acid extract of $P$. frutescens was named as PF-RAE. FTIR spectrum of PF-RAE is represented in Fig. S1 (Supplemental file). FTIR spectrum showed the major peaks at $3421.45,2917.12$, $1603.62,1378.59,1053.00$ and $557.45 \mathrm{~cm}^{-1}$. The broad peak at $3421.45 \mathrm{~cm}^{-1}$ is responsible for stretching vibrations of $\mathrm{O}-\mathrm{H}$ (hydroxyl) group of phenolic compounds. This peak indicates that PF-RAE is rich in phenolic compounds. Sharp peak at $2917.12 \mathrm{~cm}^{-1}$ is corresponding to asymmetrical stretching vibrations of methylene group $\left(v_{a}\left(\mathrm{CH}_{2}\right)\right)$ of aromatic chains of phenolic acids [25]. The peak at $1603.62 \mathrm{~cm}^{-1}$ could be due to $\mathrm{C}=\mathrm{C} / \mathrm{C}=\mathrm{O}$ stretching vibrations of phenolic acids and their derivatives $[26,27]$. The peak at $1378.59 \mathrm{~cm}^{-1}$ is responsible for $\mathrm{C}=\mathrm{C}$ bond of aromatic compounds and their chains. The peak at $1053 \mathrm{~cm}^{-1}$ could be due to $\mathrm{C}=\mathrm{O}$ stretching vibrations of ester groups [27]. The peak at $557.45 \mathrm{~cm}^{-1}$ is due to aromatic ring vibrations. FTIR profile of PF-RAE revealed that phenolic compounds are the major compounds present in PF-RAE. TPC of PF-RAE was determined using F-C method, and the TPC of PF-RAE was found to be $9.29 \mathrm{mg}$ GAE/g DW. Further, HPLC analysis of PF-RAE was carried out. HPLC profile of standard rosmarinic acid (Fig. 1a) and HPLC profile of PF-RAE were compared (Fig. 1b). HPLC profile of PF-RAE revealed a major peak at 8.942 RT which is authenticated as rosmarinic acid based on the standard profile. HPLC profile of PF-RAE revealed one clear and height peak of rosmarinic acid along with negligible smaller peaks. This clearly tells us that rosmarinic acid is the only one major component in the PF-RAE with $83.65 \%$ purity. In this investigation, the content of rosmarinic acid in the PF-RAE was found to be $7.98 \mathrm{mg} / \mathrm{g}$ DW of perilla leaf powder. Our results were in good agreement with those of previous reports. Liu et al. [28] reported that $P$. frutescens leaves from different localities of China contain rosmarinic acid from 5 to $12 \mathrm{mg} / \mathrm{g}$ DW.
Fig. 1 HPLC profile of a standard rosmarinic acid and b PF-RAE. In both profiles, rosmarinic acid was detected at RT of 8.9
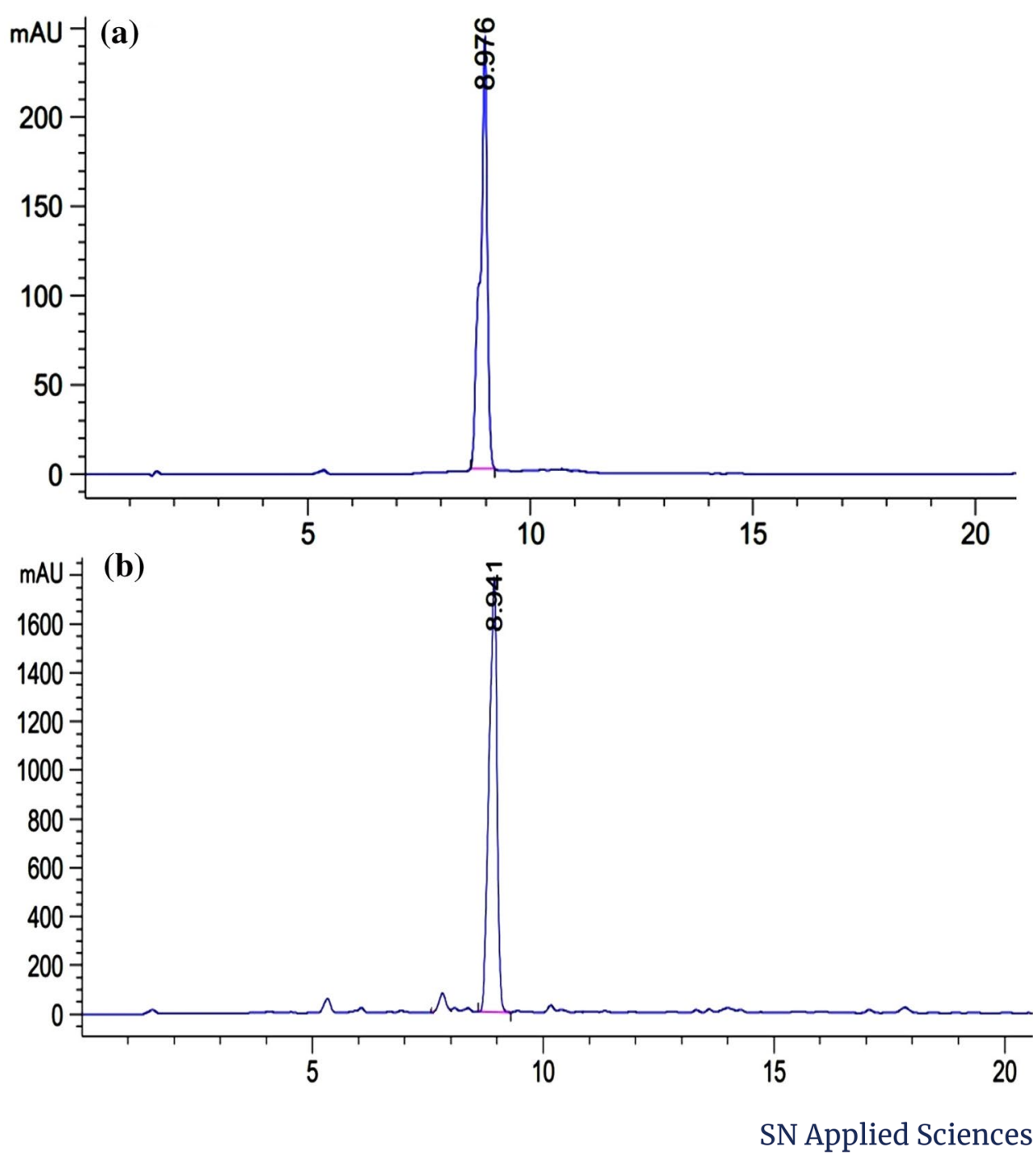
Kangwan et al. [29] reported that ethanolic extract (70\% ethanol, shaking at $150 \mathrm{rpm}$ for $12 \mathrm{~h}$ ) of $P$. frutescens contains a major component rosmarinic acid. Tang et al. [30] reported that ultrasound-assisted ethanol extract of $P$. frutescens contains rosmarinic acid as major component.

PF-RAE was evaluated for multiple biological functions including antimicrobial, antioxidant and hyaluronidase inhibitory activities using in vitro assays. Further, molecular docking studies were carried out between rosmarinic acid and peptide deformylase (promising bacterial target), between rosmarinic acid and $\mathrm{N}$-myristoyltransferase (promising fungal target) and between rosmarinic acid and human hyaluronidase proteins. Finally, pharmacokinetics, drug-likeness and toxicity studies of rosmarinic acid were carried out by in silico methods.

\subsection{Antimicrobial activity of PF-RAE}

Antibacterial activity of the PF-RAE was evaluated against Gram-negative (E. coli) and Gram-positive (S. aureus) bacteria (Fig. 2). An increase in the dosage of PF-RAE increases diameter of inhibition zones from 2 to $10 \mathrm{~mm}$ against $E$. coli and from 2 to $8 \mathrm{~mm}$ against S. aureus. PF-RAE produced maximum inhibition zones of $10 \mathrm{~mm}$ and $8 \mathrm{~mm}$ against both E. coli and S. aureus, respectively, at the highest dose used in this study. Further, antifungal activity of the PF-RAE was evaluated against $C$. albicans. PF-RAE formed maximum inhibition zone of $10 \mathrm{~mm}$. Thus, PF-RAE exhibited significant antifungal activity. Based on the HPLC profile, we determined that rosmarinic acid is the major component responsible for antimicrobial activity of PF-RAE. Further, due to the presence of hydroxyl groups, it forms hydrogen bonds with active site of major proteins and enzymes of microbes and inhibits the metabolic activities, which lead to death of microbes [31]. In this study, we also proved one of the plausible antimicrobial mechanisms by molecular docking studies between rosmarinic acid and peptide deformylase (a major enzyme of prokaryotic translation) and between rosmarinic acid and $\mathrm{N}$-myristoyltransferase (major posttranslational enzyme of fungi). Hu et al. [32] reported that rosmarinic acid and other phenolic compounds showed antibacterial activity by damaging permeability of bacterial membrane and cause the ion leakage which in turn causes loss of membrane proton motive force leading to bacterial death. The results in this study are in consistent with those in previous reports. Jarrar et al. [33] interpreted that $80 \%$ ethanol extract of Rosmarinus officinalis containing the active constituent rosmarinic acid showed inhibition against drug resistance $S$. aureus. Benedec et al. [34] reported that ethanolic extracts of Ocimum basilicum, Hyssopus officinalis, R. officinalis, Origanum vulgare, Melissa officinalis and Salvia officinalis exhibited antimicrobial activities against $S$. aureus and $C$. albicans. They reported that antimicrobial activities are due to the presence of rosmarinic acid. Moreno et al. [35] demonstrated that rosmarinic acid-rich methanol extract of $R$. officinalis showed significant inhibitory activity against bacteria (E. coli, S. aureus, B. subtilis and K. pneumoniae) and fungi (C. albicans and Saccharomyces cerevisiae). Abedini et al. [36] reported that hydromethanolic extracts of stems of Hyptis atrorubens containing rosmarinic acid exhibited antimicrobial activity against bacteria, yeast and dermatophytes. Akhtar et al. [37] reported that chloroform crude extract of Adenium obesum showed effective antimicrobial activity against different species including Proteus vulgaris, Pseudomonas aeruginosa, E. coli and S. aureus, and they revealed that antimicrobial activity of chloroform crude extract was due to the active constituent rosmarinic acid. Sweet basil (O. basilicum L.) extracts containing rosmarinic acid showed antimicrobial activity against a wide range of soil-borne bacterial and fungal pathogens [38].

\subsection{Antioxidant activity of PF-RAE}

Antioxidant activity of the PF-RAE was determined by free radical scavenging assays. PF-RAE exhibited effective antioxidant activity against the free radicals checked in this study including DPPH and ABTS radicals (Fig. 3). An
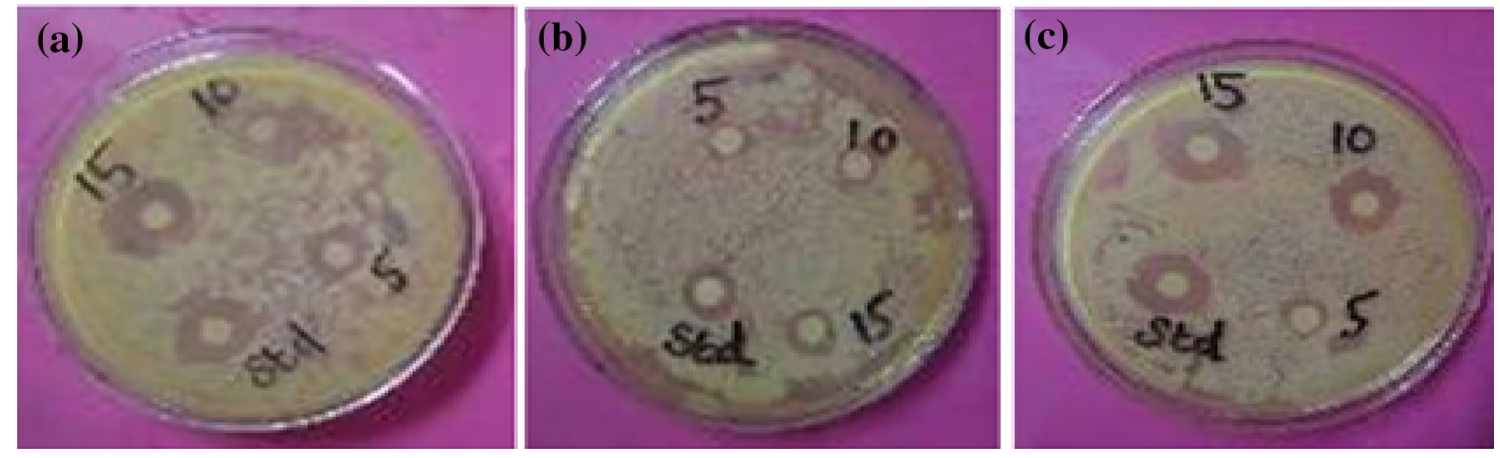

Fig. 2 Antimicrobial activity of PF-RAE against $\mathbf{a}$ S. aureus and $\mathbf{b}$ E. coli and $\mathbf{c}$ C. albicans

SN Applied Sciences 


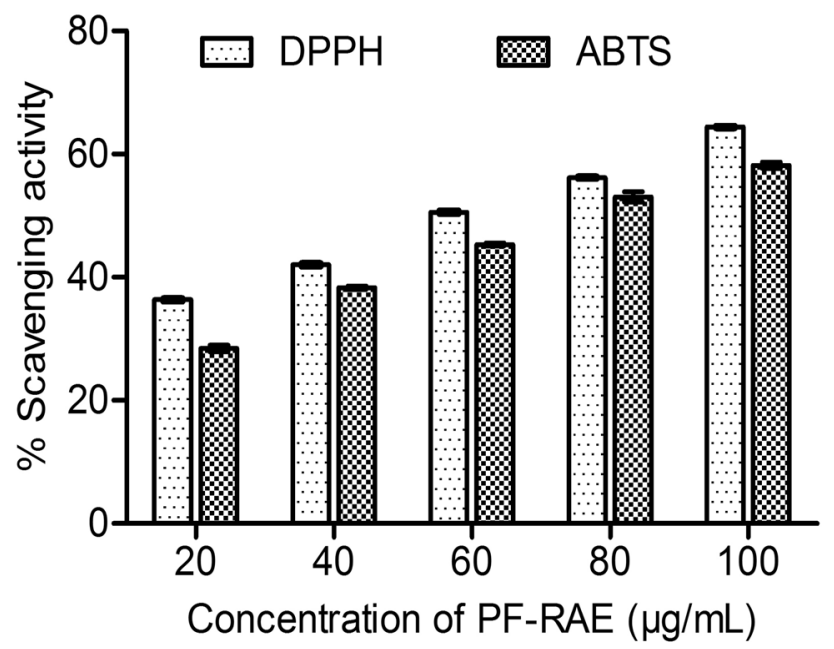

Fig. 3 Antioxidant activity of PF-RAE a DPPH radical scavenging activity and $\mathbf{b}$ ABTS radical scavenging activity

increase in the concentration of PF-RAE increased the DPPH scavenging activity, and maximum DPPH scavenging activity of $64.42 \%$ was observed at the highest concentration of $100 \mu \mathrm{g} / \mathrm{mL}$ used in this study. $I C_{50}$ value of PFRAE against DPPH free radicals was found to be $60.26 \mu \mathrm{g} /$ $\mathrm{mL}$. Further, antioxidant activity of the PF-RAE was checked against ABTS radicals. PF-RAE exhibited concentrationdependent inhibition against $A B T S$ radicals with maximum inhibition of $58.18 \%$. IC $C_{50}$ value of PF-RAE against ABTS radicals was found to be $74.38 \mu \mathrm{g} / \mathrm{mL}$. Oxidative stress or oxidative damage is due to production of reactive oxygen species and reactive nitrogen species including hydroxyl free radicals, superoxide, singlet oxygen, peroxynitrite and nitric acid free radicals [39]. These oxidant radicals have two sources both exogenous (alcohol, smoking, drugs, pesticides, radiation, industrial pollutants and heavy metals) and endogenous (peroxisomes, phagocytes, mitochondria and endoplasmic reticulum). Oxidative damage is attributed to different diseases including cancers, liver damages, pulmonary diseases, neurodegenerative diseases, cardiovascular diseases, aging and age-related diseases [40]. It is reported that rosmarinic acid and rosmarinic acid-rich extracts are nature's best answer to oxidative damages and aging-related diseases due to strong antioxidant power of rosmarinic acid. Due to its antioxidant nature, rosmarinic acid extracts could be used in the many herbal preparations including antiaging skin ointments [41, 42]. Akhtar et al. [37] confirmed that DPPH radical scavenging activity of chloroform crude extract of $A$. obesum was due to the presence of active constituent rosmarinic acid. Benedec et al. [34] reported that ethanolic extracts of $H$. officinalis, $M$. officinalis, $O$. vulgare, $O$. basilicum, $R$. officinalis and $S$. officinalis exhibited antioxidant activities by hemoglobin ascorbate peroxidase activity

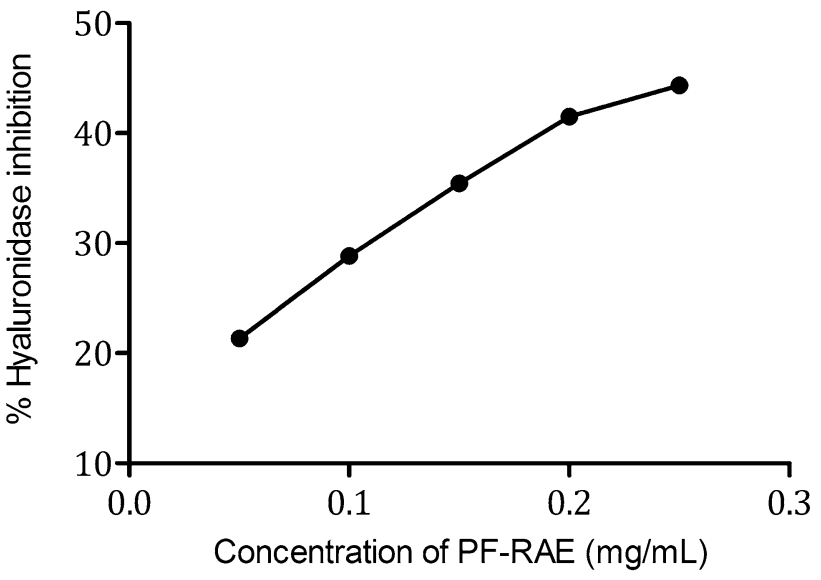

Fig. 4 Hyaluronidase inhibitory activity of PF-RAE

inhibition, DPPH scavenging and electron paramagnetic resonance methods. They reported that antioxidant activities are due to the presence of rosmarinic acid. Rosemary extracts rich in rosmarinic acid showed antioxidant activities by inhibiting and decomposition of hydroperoxides. Erkan et al. [43] demonstrated that the antioxidant activities of $R$. officinalis leaf extracts and Nigella sativa seed extracts against DPPH radicals were mainly due to the presence of rosmarinic acid. Ultrasound-assisted ethanolic extracts of $R$. officinalis, M. officinalis, S. officinalis, Malva sylvestris, Lavandula angustifolia and Hypericum perforatum showed DPPH scavenging activity due to the active constituent rosmarinic acid [44].

\subsection{In vitro hyaluronidase inhibitory activity of PF-RAE}

In the present study, PF-RAE exhibited effective in vitro hyaluronidase inhibitory activity. An increase in the concentration of PF-RAE increased the inhibition of hyaluronidase (Fig. 4). PF-RAE exhibited $44.35 \%$ inhibition at highest concentration $(0.25 \mathrm{mg} / \mathrm{mL})$ used in this study. Thus, PF-RAE exhibited dose-dependent inhibition of hyaluronidase. The results are in line with those of previous reports. Chaiyana et al. [45] reported that ethanolic extracts of Ocimum sanctum exert highest hyaluronidase inhibitory activity ( $50 \%$ of inhibition at $270.3 \pm 35.2 \mu \mathrm{g} / \mathrm{mL}$ ) and demonstrated that rosmarinic acid was major compound responsible for this activity which impart antiaging effects of $O$. sanctum. Ippoushi et al. [46] reported 46 different vegetables and herbs along with lemon balm (M. officinalis) evaluated as strong hyaluronidase inhibitors. Based on the spectroscopic method, they found that rosmarinic acid is the main component responsible for hyaluronidase inhibitory activity. Murata et al. [47] reported that Lycopus lucidus showed antiallergic effect 
thorough the inhibition of hyaluronidase. They demonstrated that hyaluronidase increased vascular permeability, which leads to mast cell degranulation, a main cause for allergic response. They reported that rosmarinic acid is one of the main components responsible for antiallergic activities of $L$. lucidus via hyaluronidase inhibition. Murata et al. [48] reported that rosmarinic acid and rosmarinic acid derivatives from Meehania urticifolia showed effective hyaluronidase inhibitory activities with $50 \%$ inhibition at concentration of 183-1049 $\mu \mathrm{M}$. Ito et al. [49] reported that rosmarinic acid from Rabdosia japonica showed antiallergic effect through by inhibiting hyaluronidase. Girish et al. [50] reported that HA degradation by hyaluronidase in extracellular matrix is related to many pathological processes including allergy, inflammation, cancer progression, migration of cancer cells, angiogenesis, envenomation and microbial pathogenesis (wound infections, pneumonia, bacteremia). Hence, inhibition of hyaluronidase is critical in hyaluronidase-mediated pathological conditions. They reported that polyphenols and flavonoids were found to be effective hyaluronidase inhibitors which serve as antiaging, antiallergic, antiinflammatory, anticancer, antimicrobial and antivenom/toxin agents. Tundis et al. [41] reported that rosmarinic acid exhibits skin antiaging effects by exhibiting hyaluronidase inhibitory activity, antityrosinase and antielastase activities. Owing to hyaluronidase inhibitory activity, rosmarinic acid acts as potential antidote to snake venom and bee toxins. McCook et al. [8] reported that hyaluronidase inhibitors may serve as antiaging, antiallergic, antioxidant and antiinflammatory compounds. They developed $\mathrm{Na}-\mathrm{Cu}$-chlorophyllin complex as antiaging cosmetic which is found to be strong inhibitor of hyaluronidase. Rosmarinic acid-rich ethanol extracts of Ocimum sanctum exert antiaging activities by exhibiting strong antioxidant and hyaluronidase inhibitory activities [45]. Several plants belonging to the genera Rosmarinus, Melissa, Perilla, Prunella, Borago, Salvia and Lithosperma have been used to treat allergic diseases since ancient days. The most active constituent responsible for antiallergic activity of the leaves of these plants was found to be rosmarinic acid. Further studies on these herbs revealed that they have strong in vivo antioxidant and immune-modulating effects due to the presence of rosmarinic acid. The leaves of $P$. frutescens have been used as antidote for allergic reactivity to fish and crab ingestion and for bronchial asthma. The antiallergic activities of leaves of $P$. frutescens are due to rosmarinic acid.

$H A$ is very important for maintaining skin very healthy, and hyaluronidase, an enzyme for the degradation of $\mathrm{HA}$, has been known to be associated with premature aging of skin due to intrinsic and extrinsic factors. Hence, hyaluronidase inhibitors are found to be skin antiaging therapies $[3,4,7]$. Hyaluronidase is known to be associated with allergy, increased vascular permeability and inflammation responses. Hyaluronidase inhibitors appear to be potent compounds which suppress allergic and inflammatory responses $[5,6]$. Reactive oxygen species formed by radiation, pollution, chemicals and dietary habits causes oxidative stress. Oxidative stress and HA degradation by hyaluronidases are two main factors for extrinsic aging. Hence, inhibition of ROS and hyaluronidase is considered as one of the mechanisms of skin antiaging [1-7]. Surely, the bioactivities of rosmarinic acid, namely antimicrobial, antioxidant and hyaluronidase inhibitory activities, revealed and support that rosmarinic acid can be developed as effective antiaging cosmetics.

\subsection{In silico studies}

\subsubsection{Molecular docking studies}

Molecular docking studies revealed that rosmarinic acid has strong binding affinity with peptide deformylase with binding score of $-7.9 \mathrm{kcal} / \mathrm{mol}$. Molecular docking of rosmarinic acid within the binding pocket of peptide deformylase was represented along with different interactions (Fig. 5). The best docking pose revealed that rosmarinic acid formed one polar interaction, four nonpolar interactions and one arene-cation interaction with key amino acid residues as well as one covalent interaction with enzyme cofactor $\mathrm{Zn}^{+2}$. His 132 bound with ligand by hydrogen bonding. Arg97 bound with ligand by arene-cation interaction. Gly43, Gly89, Cys90 and Leu91 bound with ligand by nonpolar interactions. Further, rosmarinic acid formed covalent interaction with enzyme cofactor $\mathrm{Zn}^{+2}$. Thus, rosmarinic acid strongly bound with the bacterial enzyme peptide deformylase with all possible interactions. Protein synthesis in bacteria is initiated with $\mathrm{N}$-formylmethionine residue. Following the translation, removal of formyl group (deformylation) at $\mathrm{N}$-formylmethionine of newly synthesized polypeptides is essential to make the proteins functional. Peptide deformylases catalyze the deformylation of newly synthesized polypeptides in bacteria [51, 52]. Thus, peptide deformylases are essential prokaryotic enzymes and represent a selective and promising target for the development of novel antibacterial agents. Peptide deformylases are metalloenzymes which require various inorganic metals $\left(\mathrm{Zn}^{+2} / \mathrm{Fe}^{+2} / \mathrm{Ni}^{+2}\right)$ as their cofactors. These cofactors play a catalytic role as well as important for thermodynamic stability of protein $[53,54]$. In our study, rosmarinic acid strongly bound with $\mathrm{Zn}^{+2}$ of $E$. coli peptide deformylase along with other polar and nonpolar interactions within the binding pocket of protein. Rosmarinic acid was proved to be strong inhibitor of peptide deformylase, which leads to bacterial death. Our in vitro antibacterial 


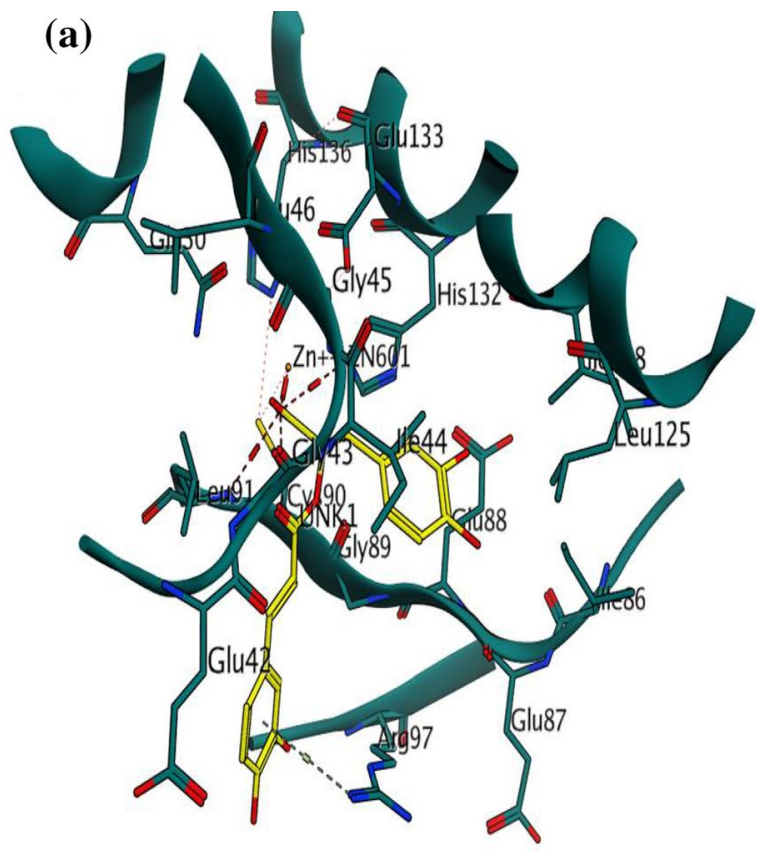

(b)
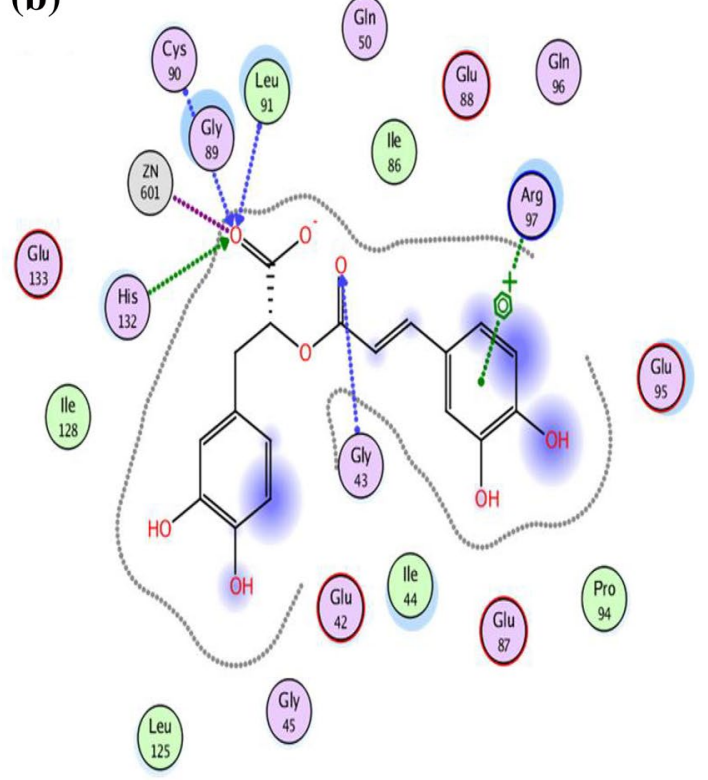

Fig. 5 The interaction of rosmarinic acid with peptide deformylase (PDBID: 1LRU) within binding site cavity represented by 3D diagram (a), and 2D diagram (b) represents different types of interactions between ligand and protein within binding pocket

activity results further support the strong antibacterial activity of rosmarinic acid.

$\mathrm{N}$-Myristoyltransferase, an eukaryotic cellular enzyme, catalyzes the transfer of a rare $\mathrm{C}_{14}$ fatty acid myristic acid from $\mathrm{N}$-myristoyl CoA to $\mathrm{N}$-terminal glycine residue of the many important eukaryotic proteins. The process is called $\mathrm{N}$-myristoylation which is an important co- and/or posttranslation modification of proteins involved in the signal transduction cascades of human fungal pathogens [55, 56]. As $N$-myristoylation is a ubiquitous process of fungal proteins, $\mathrm{N}$-myristoyltransferase became a selective and promising antifungal target for the development of novel fungal inhibitors $[57,58]$. In this study, we have carried out molecular docking between rosmarinic acid and active site of $\mathrm{N}$-myristoyltransferase. The best docking configuration and the binding interactions with key amino acid residues of binding packet of $N$-myristoyltransferase are shown in Fig. 6. The best docking pose within the binding pocket of $\mathrm{N}$-myristoyltransferase revealed that rosmarinic acid formed one hydrogen bond interaction with Tyr354 and hydrophobic interactions with other key residues. Rosmarinic acid has strong binding affinity with $\mathrm{N}$-myristoyltransferase with binding score of $-7.1 \mathrm{kcal} / \mathrm{mol}$. Thus, in silico studies revealed that rosmarinic acid was strong inhibitor of $\mathrm{N}$-myristoyltransferase.

Hyaluronidase, an enzyme for the degradation of $\mathrm{HA}$, involved in skin aging, allergy, inflammation, enhancing vascular permeability, angiogenesis, carcinogenesis, metastasis and migration of cancer cells. Hyaluronidase became target for the development of novel therapeutics for the suppression of allergy, inflammation, tumor cell growth and metastasis [1-7]. Further, hyaluronidase becomes promising target for the development of skin antiaging cosmeceutics [7]. In this study, we proved that rosmarinic acid was found to be significant inhibitor of hyaluronidase through in vitro assay. Further, we have carried out molecular docking studies between rosmarinic acid and human hyaluronidase. Docking studies revealed that rosmarinic acid was bound within the binding pocket of hyaluronidase with four binding interactions represented in Fig. 7. The binding affinity was found to be -5 . $9 \mathrm{kcal} / \mathrm{mol}$. Rosmarinic acid formed two H-bonds with Arg134 and Asp206, one nonpolar bond with Tyr247, one covalent interaction with Arg134, and other amino acid residues within the binding pocket formed hydrophobic interactions with the ligand rosmarinic acid. The binding score and binding interactions revealed that rosmarinic acid was found to be a strong hyaluronidase inhibitor. Molecular docking studies were supported by our in vitro results as well as those of previous studies. These studies disclosed that rosmarinic acid acts as a strong hyaluronidase inhibitor.

\subsubsection{Drug-likeness evaluation of rosmarinic acid}

The physicochemical properties of rosmarinic acid were found to be Mol. Wt of 360.31, nON of $8, \mathrm{nOHNH}$ of 5 , TPSA of $144.52 \mathrm{~A}^{2}$, nrotb of 7, Log Po/w of 1.52 and Log 


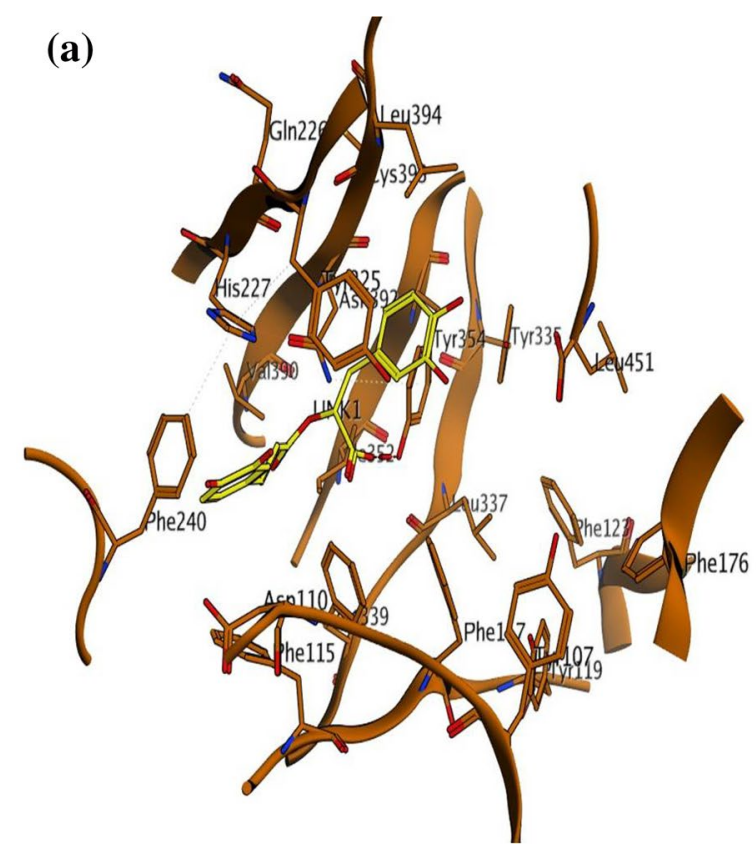

(b)

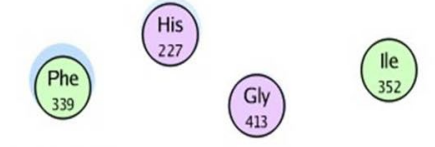

(Leu

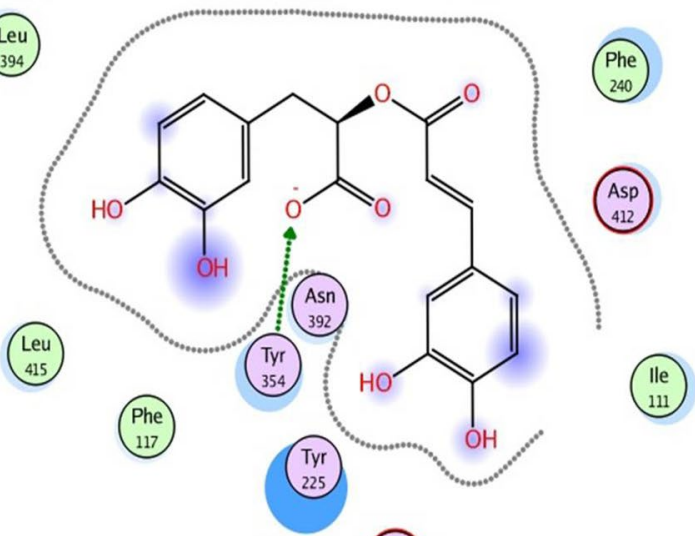

(Asp

(Asp

Fig. 6 Molecular docking of rosmarinic acid within C. albicans $N$-myristoyltransferase (PDBID: 1IYL) binding site cavity represented by 3D diagram (a), and 2D diagram (b) represents interactions within binding pocket

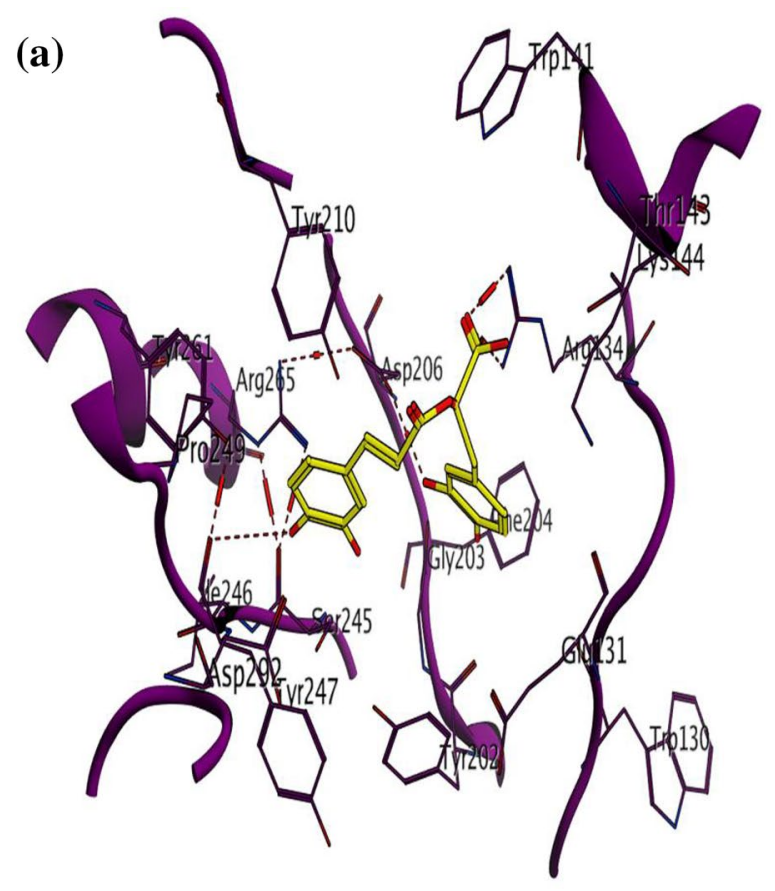

(b)

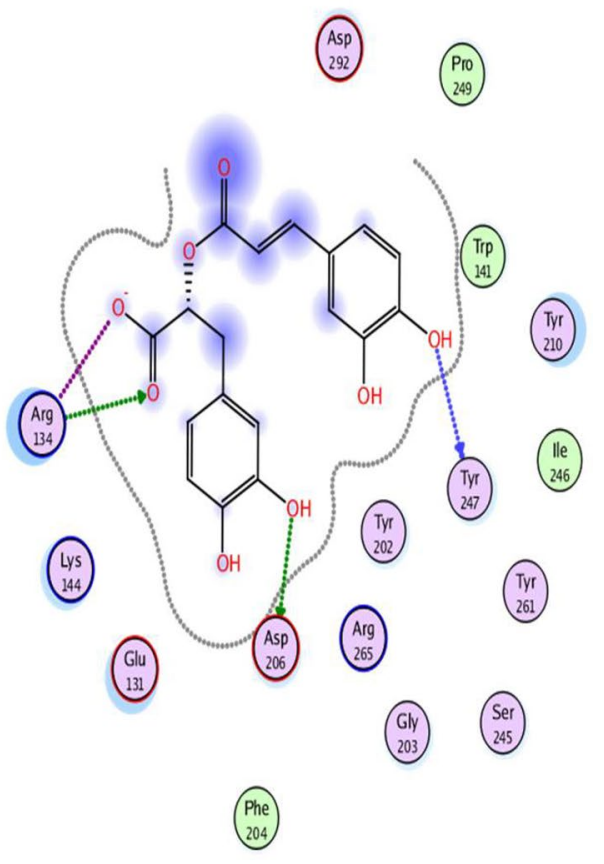

Fig. 7 Binding of rosmarinic acid within binding pocket of human hyaluronidase (PDBID: 2PE4) represented by 3D diagram (a), and 2D diagram (b) represents different interactions within binding cleft

Table 1 Lipinski's rule of five for rosmarinic acid predicted by SwissADME software

\begin{tabular}{lllllllll}
\hline Mol. wt & nON & nOHNH & nrotb & TPSA & Volume & Log Po/w & Log $S$ & $\log K p$ \\
\hline 360.31 & 8 & 5 & 7 & 144.52 & 303.54 & 1.52 & -2.17 & $-6.82 \mathrm{~cm} / \mathrm{s}$ \\
\hline
\end{tabular}


S of - 2.17 (Table 1). The values of $\mathrm{Mol}, \mathrm{Wt}, \mathrm{nON}, \mathrm{nOHNH}$, TPSA, nrotb and Log Po/w clearly indicated that rosmarinic acid perfectly obeys Lipinski's rule of five with no violations (' 0 ' violation). Lipinski's rule of five is an important parameter to assess the oral bioavailability of a compound or drug. In this study, rosmarinic acid satisfactorily follows the Lipinski's parameter of drug-likeness evaluation. Further, the lower Log Po/w value (1.52) indicated no lipophilicity and higher hydrophilic nature of rosmarinic acid. Log $S$ value indicated its good solubility in water. Bioavailability, absorption, permeability and distribution of a compound can be determined by major determinants including TPSA, $\mathrm{nON}, \mathrm{nOHNH}, \mathrm{nrotb}, \mathrm{Log} \mathrm{Po} / w$ and Log S. All these values are within the range of Lipinski's rule, indicating good oral bioavailability, absorption and permeability of rosmarinic acid. Rosmarinic also showed very well skin permeation
(Log $K p$ ) with predicted value of $-6.82 \mathrm{~cm} / \mathrm{s}$ (Table 1). Rosmarinic acid showed good human gastrointestinal absorption and medium blood-brain barrier penetration with probabilities of, respectively, 0.7243 and 0.6095 (Table 2). Excretion of a compound from the body depends on the molecular weight and Log Po/w. Small molecular weight and hydrophilic nature of rosmarinic acid indicate rapid renal clearance and excretion.

ADMET studies by admetSAR and Osiris server indicated that rosmarinic acid exhibited no risk of mutagenicity, no risk of skin irritation and no risk of reproductive toxic effects (Table 3). Further, it is proved to be non-carcinogenic, and non-AMES toxic. The other toxic parameters of rosmarinic acid are depicted in Table 2. All these studies indicated that rosmarinic acid complies with all toxicity risk assessment parameters. The cytochrome P450 system
Table 2 ADMET prediction profile of rosmarinic acid by admetSAR data

\begin{tabular}{|c|c|c|}
\hline Property & Predicted result & Probability \\
\hline \multicolumn{3}{|l|}{ Absorption } \\
\hline Blood-brain barrier & $\mathrm{BBB}+$ & 0.6095 \\
\hline Human intestinal absorption & $\mathrm{HIA}+$ & 0.7243 \\
\hline Caco-2 permeability & Caco2- & 0.8957 \\
\hline$P$-glycoprotein substrate & $\begin{array}{l}\text { Substrate } \\
\text { Non-inhibitor }\end{array}$ & $\begin{array}{l}0.5223 \\
0.8278\end{array}$ \\
\hline P-glycoprotein inhibitor & Non-inhibitor & 0.8750 \\
\hline Renal organic cation transporter & Non-inhibitor & 0.8941 \\
\hline \multicolumn{3}{|l|}{ Distribution } \\
\hline Subcellular localization & Mitochondria & 0.8306 \\
\hline \multicolumn{3}{|l|}{ Metabolism } \\
\hline CYP450 2C9 substrate & Non-substrate & 0.7660 \\
\hline CYP450 2D6 substrate & Non-substrate & 0.9035 \\
\hline CYP450 3A4 substrate & Non-substrate & 0.6114 \\
\hline CYP450 1A2 inhibitor & Non-inhibitor & 0.6279 \\
\hline CYP450 2C9 inhibitor & Non-inhibitor & 0.8754 \\
\hline CYP450 2D6 inhibitor & Non-inhibitor & 0.9231 \\
\hline CYP450 2C19 inhibitor & Non-inhibitor & 0.9026 \\
\hline CYP450 3A4 inhibitor & Non-inhibitor & 0.8309 \\
\hline CYP inhibitory promiscuity & Low CYP inhibitory promiscuity & 0.8300 \\
\hline \multicolumn{3}{|l|}{ Toxicity } \\
\hline $\begin{array}{l}\text { Human ether-a-go-go-related gene inhibi- } \\
\text { tion }\end{array}$ & $\begin{array}{l}\text { Weak inhibitor } \\
\text { Non-inhibitor }\end{array}$ & $\begin{array}{l}0.9597 \\
0.8234\end{array}$ \\
\hline AMES toxicity & Non AMES toxic & 0.7412 \\
\hline Carcinogens & Non-carcinogens & 0.9414 \\
\hline Fish toxicity & High FHMT & 0.9967 \\
\hline Tetrahymena pyriformis toxicity & High TPT & 0.9967 \\
\hline Honeybee toxicity & High HBT & 0.6511 \\
\hline Biodegradation & Not readily biodegradable & 0.6207 \\
\hline Acute oral toxicity & III & 0.7720 \\
\hline Carcinogenicity (three classes) & Non-required & 0.6152 \\
\hline Rat acute toxicity & $\mathrm{LD} 50, \mathrm{~mol} / \mathrm{kg}$ & 2.3234 \\
\hline Fish toxicity & 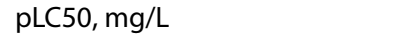 & -0.1231 \\
\hline Tetrahymena pyriformis toxicity & $\mathrm{plGC50,ug/L}$ & 0.8320 \\
\hline
\end{tabular}


Table 3 Toxicity risk properties of rosmarinic acid evaluated by Osiris property explorer

\begin{tabular}{|c|c|c|c|c|c|}
\hline $\begin{array}{l}\text { Com- } \\
\text { pound }\end{array}$ & Mutagenic & $\begin{array}{l}\text { Tumori- } \\
\text { genic/car- } \\
\text { cinogenic }\end{array}$ & Irritant & $\begin{array}{l}\text { Reproduc- } \\
\text { tive/devel- } \\
\text { opmental } \\
\text { toxicity }\end{array}$ & $\begin{array}{l}\text { AMES } \\
\text { toxic- } \\
\text { ity }\end{array}$ \\
\hline $\begin{array}{l}\text { Ros- } \\
\text { marinic } \\
\text { acid }\end{array}$ & No risk & No risk & No risk & No risk & No \\
\hline
\end{tabular}

contains different enzymes including CYP450 1A2, CYP450 2C9, CYP450 2C19, CYP450 2D6 and CYP450 3A4. These enzymes are very important for detoxification of foreign materials and metabolism of drugs in the liver. CYP inhibitors act on the CYP450 enzymes and slow or stop their activity. In silico studies revealed that rosmarinic acid satisfactorily clears CYP450 screening test and found to be non-substrate and non-inhibitor of CYP450 enzymes (Table 2). Further, bioactivity score of rosmarinic acid was calculated by Molinspiration and is given in Table 4 . Bioactivity score of rosmarinic acid was found to be 0.17 for GPCR ligand, 0.57 for nuclear receptor ligand, -0.08 for ion channel modulator, -0.18 for kinase inhibitor, 0.15 for protease inhibitor and 0.24 for enzyme inhibitor. If the bioactivity score is > 0.0 , then the compound is highly active. If the score is between 0.0 and -5.0 , then it is active, and if the score is less than -5 , then it is inactive. In this study, the bioactivity score for rosmarinic acid was found between -1 and 1 . The in silico results indicated the potential bioactivity of rosmarinic acid. In the investigation of drug-likeness evaluation of rosmarinic acid (Table 5), it is revealed that rosmarinic acid shows no violations of Lipinski's rule, showed well oral bioavailability, was easily soluble in water and showed good intestinal absorption, good skin permeation and moderate blood-brain barrier permeation. Based on SwissADME study, bioavailability of rosmarinic acid was found to be 0.56 , which indicates that rosmarinic acid can be developed and used as a drug or drug ingredient/pharmaceutical ingredient/nutraceutical ingredient. These results are in line with those of previous reports. It was reported that rosmarinic acid was well absorbed from gastrointestinal tract, showed well skin permeation capacity and was rapidly excreted in the urine [59, 60]. It is also reported that rosmarinic acid could be assimilated by all major organs with the highest concentration in lungs. This might be the reason that why plants with concentrations of rosmarinic acid are traditionally used to treat atopic dermatitis, eczema, asthma, other skin and respiratory allergies.

\section{Conclusion}

In the present study, we prepared rosmarinic acid extract (PF-RAE) from $P$. frutescens leaves by ultrasound-assisted method using ethanol solvent. PF-RAE exhibited effective antimicrobial activity against Gram-negative (E. coli), Gram-positive (S. aureus) and fungal pathogen (C. albicans). PF-RAE showed effective antioxidant activity and significant in vitro hyaluronidase inhibitory activities. HPLC analysis determined that rosmarinic acid is the major component of extract which was responsible for these biological activities. Molecular docking studies revealed that rosmarinic acid effectively inhibited promising bacterial target enzyme (peptide deformylase), fungal target enzyme ( $N$-myristoyltransferase) and human hyaluronidase enzyme. Further, rosmarinic acid follows Lipinski's rule and satisfies all the drug-likeness and pharmacokinetics parameters including water solubility, oral bioavailability skin permeation, human intestinal absorption, blood-brain barrier permeation, no toxicity and bioactivity scores. The results support that rosmarinic acid can be developed as an effective cosmeceutical, pharmaceutical and nutraceutical component or an ingredient.

Table 4 Bioactivity score of rosmarinic acid predicted by Molinspiration software

\begin{tabular}{lllllll}
\hline Compound & GPCR ligand & Nuclear receptor ligand & lon channel modulator & Kinase inhibitor & Protease inhibitor & Enzyme inhibitor \\
\hline Rosmarinic acid & 0.17 & 0.57 & -0.08 & -0.18 & 0.15 & 0.24 \\
\hline
\end{tabular}

Table 5 Drug-likeness evaluation of rosmarinic acid

\begin{tabular}{|c|c|c|c|c|c|c|}
\hline Compound & Water solubility & Oral bioavailable & $\begin{array}{l}\text { Gastro intestinal absorp- } \\
\text { tion }\end{array}$ & BBB permeation & Lipinski rule of five & Bio availability score \\
\hline Rosmarinic acid & Soluble & Yes & Yes & Yes & No violation & 0.56 \\
\hline
\end{tabular}


Acknowledgements This work was supported by Key Research and Development (R\&D) Projects of Shanxi Province (201803D31060), China.

\section{Compliance with ethical standards}

Conflict of interest All the authors read, approved and consented to publish this manuscript and also declared that there are no personal and financial conflicts of interest.

\section{References}

1. Laurent TC, Fraser JR (1992) Hyaluronan. FASEB J 6:2397-2404

2. Juhlin $L$ (1997) Hyaluronan in skin. J Intern Med 242:61-66

3. Allemann IB, Baumann L (2008) Hyaluronic acid gel (Juvéderm ${ }^{\mathrm{TM}}$ ) preparations in the treatment of facial wrinkles and folds. Clin Interv Aging 3:629-634

4. Farage MA, Miller KW, Elsner P, Maibach HI (2008) Intrinsic and extrinsic factors in skin ageing, a review. Int J Cosmet Sci 30:87-95

5. Stern R, Jedrzejas MJ (2006) The hyaluronidases, their genomics, structures, and mechanisms of action. Chem Rev 106:818-839

6. Mio K, Stern R (2002) Inhibitors of the hyaluronidases. Matrix Biol 21:31-37

7. Papakonstantinou E, Michael R, Karakiulakis G (2012) Hyaluronic acid a key molecule in skin aging. Dermatoendocrinology $4: 253-258$

8. McCook JP, Dorogi P, Vasily DB, Cefalo DR (2015) In vitro inhibition of hyaluronidase by sodium copper chlorophyllin complex and chlorophyllin analogs. Clin Cosmet Investig Dermatol 8:443-448

9. Nawy SS, Csóka AB, Mio K, Stern R (2001) Hyaluronidase activity and hyaluronidase inhibitors assay using a microtiter-based system. Methods Mol Biol 171:383-389

10. Hahn L (1952) Inhibitors of hyaluronidase. Nature 170:282-283

11. Hahn L, Thune S, Truedsson E (1952) Clinical investigation of the value of synthetic hyaluronidase inhibitors in rheumatoid arthritis. Ann Rheum Dis 11:272-276

12. Heci $Y$ (2001) Valuable ingredients from herb perilla, a mini review. Innov Food Technol 29-30:32-33

13. Lee JH, Park KH, Lee MH, Kim HT, Seo WD, Kim JY, Baek IY, Jang DS, Ha TJ (2013) Identification, characterization, and quantification of phenolic compounds in the antioxidant activity-containing fraction from the seeds of Korean perilla (Perilla frutescens) cultivars. Food Chem 136:843-852

14. Lee JK, Ohnishi O (2001) Geographic differentiation of morphological characters among perilla crops and their weedy types in East Asia. Breed Sci 51:247-255

15. Yu H, Qiu J-F, Ma L-J, Hu Y-J, Peng L, Jian-Bo W (2017) Phytochemical and phytopharmacological review of Perilla frutescens L. (Labiatae), a traditional edible-medicinal herb in China. Food Chem Toxicol 108:375-391

16. Jun HI, Kim BT, Song GS, Kim YS (2014) Structural characterization of phenolic antioxidants from purple perilla (Perilla frutescens var. acuta) leaves. Food Chem 148:367-372

17. Zhou J, Zhang L, Li Q, Jin W, Chen W, Han J, Zhang Y (2019) Simultaneous optimization for ultrasound-assisted extraction and antioxidant activity of flavonoids from Sophora flavescens using response surface methodology. Molecules 24:112

18. Singleton VL, Orthofer R, Rosa ML (1999) Analysis of total phenols and other oxidation substrates and antioxidants by means of Folin-Ciocalteu reagent. Methods Enzymol 299:152-178
19. Lopez-Amotdos M, Lopez-Serrano A, Barcelo RAA (1995) Spectrophotometric determination of rosmarinic acid in plant cell cultures by complexation with $\mathrm{Fe}^{2+}$ ions. Fresenius J Anal Chem 351:311-314

20. Bauer AW, Kirby WM, Sherries JC, Turck M (1966) Antibiotic susceptibility testing by a standardized single disk method. Am J Clin Pathol 45:493-496

21. Schroder T, Gaskin S, Ross K, Whiley H (2017) Antifungal activity of essential oils against fungi isolated from air. Int J Occup Environ Health 23:181-186

22. Shimada K, Fujikawa K, Yahara K, Nakamura T (1992) Antioxidative properties of xanthin on autooxidation of soybean oil in cyclodextrin emulsion. J Agric Food Chem 40:945-948

23. Re R, Pellegrini N, Proteggente A, Pannala A, Yang M, RiceEvans C (1999) Antioxidant activity applying an improved ABTS radical cation decolorization assay. Free Radic Biol Med 9-10:1231-1237

24. Morgan WT, Elson LA (1934) A colorimetric method for the determination of $n$-acetylglucosamine and $n$-acetylchrondrosamine. Biochem J 28:988-995

25. Heredia-Guerrero JA, Benítez JJ, Domínguez E, Bayer IS, CingoIani R, Athanassia A, de Antonio H (2014) Infrared and Raman spectroscopic features of plant cuticles: a review. Front Plant Sci 5:305

26. Dinakaran SK, Chelle S, Avasarala H (2019) Profiling and determination of phenolic compounds in poly herbal formulations and their comparative evaluation. J Tradit Complement Med 9:319-327

27. Oliveira RN, Mancini MC, de Oliveira FCS, Passos TM, Quilty B, Thire RMDM, McGuinness GB (2016) FTIR analysis and quantification of phenols and flavonoids of five commercially available plants extracts used in wound healing. Matéria (Rio J) 21:3

28. Liu J, Yuklam W, Zhongzhen Z, Hubiao C (2013) Determination of the content of rosmarinic acid by HPLC and analytical comparison of volatile constituents by GC-MS in different parts of Perilla frutescens (L.) Britt. Chem Cent J 7:61

29. Kangwan N, Pintha K, Lekawanvijit S, Suttajit M (2019) Rosmarinic acid enriched fraction from Perilla frutescens leaves strongly protects indomethacin-induced gastric ulcer in rats. Biomed Res Int 2019:13

30. Tang W, Sun B, Zhao Y (2014) Preparative separation and purification of rosmarinic acid from perilla seed meal via combined column chromatography. J Chromatogr B 947-948:41-48

31. Beuchat LR, Golden DA (1989) Antimicrobials occurring naturally in foods. Food Technol 43:134-142

32. Hu D-P, Jun-Ru Z, Yun-Zhi G, Hong-Xi X, Xiao-Qian L (2015) Antibacterial and membrane-damaging activities of rosmarinic acid against pathogenic organisms of acne. Lat Am J Pharm 34:1866-1870

33. Jarrar N, Abu-Hijleh A, Adwan K (2010) Antibacterial activity of Rosmarinus officinalis $\mathrm{L}$. alone and in combination with cefuroxime against methicillin-resistant Staphylococcus aureus. Asian Pac J Trop Med 3:121-123

34. Benedec D, Hanganu D, Oniga I, Tiperciuc B, Olah NK, Raita O, Bischin C, Silaghi-Dumitrescu R, Vlase L (2015) Assessment of rosmarinic acid content in six Lamiaceae species extracts and their antioxidant and antimicrobial potential. Pak J Pharm Sci 28:2297-2303

35. Moreno S, Scheyer T, Catalina SR, Adrián AV (2006) Antioxidant and antimicrobial activities of rosemary extracts linked to their polyphenol composition. Free Radic Res 40:223-231

36. Abedini $A$, Vincent $R$, Séverine $M$, Murielle $B$, Standaert-Vitse $A$ Céline R, Sevser S, François B, Christel N, Hennebelle T (2013) Rosmarinic acid and its methyl ester as antimicrobial components of the hydromethanolic extract of Hyptis atrorubens Poit (Lamiaceae). Evid Based Complement Altern Med 2013:11 
37. Akhtar MS, Hossain MA, Said SA (2017) Isolation and characterization of antimicrobial compound from the stem-bark of the traditionally used medicinal plant Adenium obesum. J Tradit Complement Med 7:296-300

38. Bais HP, Travis SW, Herbert PS, Jorge MV (2002) Root specific elicitation and antimicrobial activity of rosmarinic acid in hairy root cultures of Ocimum basilicum. Plant Physiol Biochem 40:983-995

39. Pham-Huy LA, He H, Pham-Huy C (2008) Free radicals, antioxidants in disease and health. Int J Biomed Sci 4:89-96

40. Young I, Woodside J (2001) Antioxidants in health and disease. J Clin Pathol 54:176-186

41. Tundis R, Loizzo MR, Bonesi M, Menichini F (2015) Potential role of natural compounds against skin aging. Curr Med Chem 22:1515-1538

42. Cigdem Y, Karatoprak GS, Değim IT (2019) Anti-aging formulation of rosmarinic acid-loaded ethosomes and liposomes. $J$ Microencapsul 36:180-191

43. Erkan N, Guler A, Erol A (2008) Antioxidant activities of rosemary (Rosmarinus officinalis L.) extract, blackseed (Nigella sativa L.) essential oil, carnosic acid, rosmarinic acid and sesamol. Food Chem 110:76-82

44. Nicolai M, Paula P, Rute FV, Catarina PR, Amilcar R, Patrícia R (2016) Antioxidant activity and rosmarinic acid content of ultrasound-assisted ethanolic extracts of medicinal plants. Measurement 89:328-332

45. Chaiyana W, Songyot A, Chanun P, Waranya N, Lee KH, Wei-Chao L, Shang-Chian L, Helmut V, Monika M (2019) Ocimum sanctum Linn. as a natural source of skin anti-ageing compounds. Ind Crops Prod 127:217-224

46. Ippoushi K, Yamaguchi Y, Itou H, Azuma K, Higashio H (2000) Evaluation of inhibitory effects of vegetables and herbs on hyaluronidase and identification of rosmarinic acid as a hyaluronidase inhibitor in lemon balm (Melissa officinalis I.). Food Sci Technol Res 6:74-77

47. Murata T, Miyase T, Fumihiko Y (2011) Hyaluronidase inhibitory rosmarinic acid derivatives from Meehania urticifolia. Chem Pharm Bull 59:89-95

48. Murata T, Watahiki M, Tanaka Y, Miyase T, Yoshizaki F (2010) Hyaluronidase inhibitors from Takuran, Lycopus lucidus. Chem Pharm Bull 58:394-397
49. Ito H, Miyazaki T, Makoto O, Hiromu S (1998) Antiallergic activities of rabdosiin and its related compounds, chemical and biochemical evaluations. Bioorganic Med Chem 6:1051-1056

50. Girish KS, Kemparaju K, Nagaraju S, Vishwanath BS (2009) Hyaluronidase Inhibitors, a biological and therapeutic perspective. Curr Med Chem 16:2261-2288

51. Adams JM (1968) On the release of the formyl group from nascent protein. J Mol Biol 33:571-589

52. Livingston DM, Leder $P$ (1969) Deformylation and protein synthesis. Biochemistry 8:435-443

53. Giglione C, Pierre M, Meinnel T (2000) Peptide deformylase as a target for new generation, broad spectrum antimicrobial agents. Mol Microbiol 36:1197-1205

54. Meinnel T, Blanquet S (1995) Enzymatic properties of Escherichia coli peptide deformylase. J Bacteriol 177:1883-1887

55. Boutin JA (1997) Myristoylation. Cell Signal 9:15-35

56. Rudnick DA, McWherter CA, Gokel GW, Gordon JI (1993) Myristoyl CoA, protein $\mathrm{N}$-myristoyltransferase. Adv Enzymol Relat Areas Mol Biol 67:375-430

57. Fang W, David AR, Olawale GR, David EB, Justin RH, Deborah EAL, Leah ST, Ruda GF, Wyatt PG, lan HG, Daan MFV (2015) N-Myristoyltransferase is a cell wall target in Aspergillus fumigatus. ACS Chem Biol 10:1425-1434

58. Knoll LJ, Johnson DR, Bryant ML, Gordon JI (1995) Functional significance of myristoyl moiety in $\mathrm{N}$-myristoyl proteins. Methods Enzymol 250:405-435

59. Al-Sereiti MR, Abu-Amer KM, Sen P (1999) Pharmacology of rosemary (Rosmarinus officinalis Linn.) and its therapeutic potentials. Indian J Exp Biol 37:124-130

60. Baba S, Osakabe N, Natsume M, Yasuda A, Muto Y, Hiyoshi K, Takano H, Yoshikawa T, Terao J (2005) Absorption, metabolism, degradation and urinary excretion of rosmarinic acid after intake of Perilla frutescens extract in humans. Eur J Nutr 44:1-9

Publisher's Note Springer Nature remains neutral with regard to jurisdictional claims in published maps and institutional affiliations. 